\title{
A study of some aspects of Antenatal Care following Lot Quality Techniques in the villages of Amdanga Block, West Bengal
}

\author{
${ }^{1}$ Dr Rivu Basu, ${ }^{2}$ Dr Sreetama Banerjee, ${ }^{3}$ Dr BaisakhiMaji, ${ }^{4}$ Dr Debjit Sarkar, \\ ${ }^{5}$ Dr Sudhanshu Saha Roy, ${ }^{6}$ Dr Subhadip Das, ${ }^{7}$ Prof Saibendu Kumar Lahiri
}

\begin{abstract}
A Cross sectional observational study was performed for two months from December 2013 to January 2014 in 81 villages in Amdanga Block, North 24 Parganas by Lot Quality Sampling Technique to estimate some aspects of Antenatal Care. The poorly performing lots were identified and the coverage of various services were ascertained and also the different motivators of the mothers were identified by this study. A total of 567 samples were collected by appropriate techniques. Only two of them did not take antenatal visit. 83.9\% were motivated by early ANC, mostly by the ASHAs and mother-in-laws. Most of them went to sub centres, and were registered by ANMs. Also most of them (83.9\%) registered early for ANC. The coverage of various services among the mother was satisfactory, and was found to have improved than NFHS-3, though the number of poorly performing lots as per set criteria was found to be as high as $25 \%$.
\end{abstract}

Keywords: Lot Quality sampling, Antenatal care

\section{Introduction}

Antenatal care (ANC) helps in getting a healthy mother and a healthy baby at the end of pregnancy. This requires early registration of mother and a host of services as ANC package like IFA tablets, Tetanus toxoid, advices (regarding diet, rest) etc. It is a very important service offered to mothers in their Antenatal period of all the sections of society, especially to the vulnerable sections, for perpetuation of mankind. This requires close monitoring from time to time. A cross-sectional study using lot quality technique was undertaken among a sample of 198 women in 18 sub-centers (lots) of Bankura-I Community Development Block who had delivered in last 12 months preceding the survey to find out the sub-center(s) with 'acceptable' coverage $(>$ or $=$ $50 \%$ ) and overall coverage of 'appropriate' antenatal care of the block. Out of 18 sub-centers, only one had 'acceptable' coverage of appropriate antenatal care ${ }^{[1]}$. Also NFHS-3 did an in depth review of antenatal services. It showed $56.5 \%$ of ANC registrations of West Bengal by doctors followed by ANMs $(29.5 \%)^{[2]}$. However, NFHS-4 data are yet to arrive and the impact of NRHM on the ANC is yet to be ascertained properly. Though many studies are available regarding the factors influencing antenatal outcomes in India like distance, age, education, parity of mother, ${ }^{[3,4]}$, the motivating persons are not mentioned explicitly in any of them.

With this background, this study was carried out using the Lot Quality Technique ${ }^{[5]}$, with the objectives of assessing the different aspects of antenatal care and finding out the number of poorly performing lots along with the types of motivators.

\section{Materials and Methods}

The study was conducted for two months from December 2013 to January 2014 in 81 villages in Amdanga Block, North 24 Parganas, West Bengal, the field practice area of R G Kar Medical College. It was an observational, cross sectional studyapplying the Lot Quality Technique (described by WHO). The total number of Antenatal mothers in the block was 3531. With desired level of accuracy $\pm 5 \%$ and desired confidence $99 \%$, sample size was calculated to be 663 mothers. Thus sampling fraction was calculated to be $663 / 3531 \times 100=19 \%$. As it was greater than $10 \%$, the final estimate of sample size was approximately found to 567 mothers. Thus from each village, 7 mothers were surveyed for their AnteNatal care. The data were collected in a predesigned pretested, semistructured schedule. The study was passed by the Institution Ethics committee and work commenced after taking proper permission from District authorities. On reaching each village, the centre of the village was sought, and then sampling started from there. Data were entered, compiled, cleaned and analysed using Epi Info 7. Registration before 12 weeks, three antenatal check-ups with checking of BP, weight, edema and abdominal examination, distribution of 100 IFA tablets and appropriate tetanus prophylaxis were taken collectively as criteria of appropriate' antenatal care.

\section{Results}

The results are given in the tables below. The number of poorly performing lots as per criteria set was found to be as high as 20 of 81 (24.7\%). Only 2 of 567 mothers did not register for Antenatal care. 
Mothers of age 16-20 years were highest (40.7\%) in number, and mothers of age group 36-40 formed the second highest (38.3\%) group. Most of the respondents were Muslims (62.1\%), general castes (80.6\%), and had joint family $(80.2 \%)$. The per capita income was Rs 1010, and it varied highly ( $\mathrm{SD}=\mathrm{Rs} 788$ ), with total number of living issues roughly equal to two/mother.

$83.9 \%$ of them were motivated for early ANC. The ASHA motivated 38.9\% of them followed by their mother in laws $27.5 \% .97 .3 \%$ of those who were motivated attended and registered early for ANC. About $80.3 \%$ of them were registered by ANMs. $74.8 \%$ were registered in the sub centres, and $15.9 \%$ in Private clinics by doctors. The mean month of registration of pregnancy was 3, and on an average they received 6 ANCs.About the package of services for those who were registered, all of them had their BP checked atleast once, weight taken atleast once and given some form of iron. Other services like TT immunisation, abdomen examination, advice regarding rest and diet were also offered to most of the mothers. They reported of having received on an average 90 IFA (SD 38) tablets and consumed 75 (SD 43) of them. Most of them were correctly able to recall about 3 danger signs of pregnancy.

\section{Discussions}

The study done by S. Pal et al. has showed thatthe overall coverage of 'appropriate' antenatal care was $29.1 \%$ in the study Block ${ }^{[1]}$. NFHS $3^{[2]}$ showed that in West Bengal $91.9 \%$ had atleast one ANC visit , $62.0 \%$ had three or more Antenatal Visits, $38.6 \%$ had early registration for pregnancy, $40.8 \%$ can recall the complications of pregnancy, $90.9 \%$ had appropriate TT immunisation, $81.9 \%$ were given or bought IFA tablets, percentage of pregnant women who took IFA for more than 90 days were 25.7. As evident from the study all of the parameters had improved in this block of West Bengal than those found in the the last NFHS-3. Also, the persons who have mostly motivated the mothers, as per this study, are the ASHAs and mother-in-laws.

However due to time constraint, only a block could be covered. Also the Lot Quality Technique does not allow for external validity. But if this study can be replicated in a larger population, a real impact of NRHM on rural West Bengal can be established with regards to ANC.

\section{Conflict of Interest:}

None declared

\section{Acknowledgements}

Dr Ritu Ghosh, Assistant Professor, Department of Community Medicine, R G Kar Medical College

Table 1: The socio demographic characteristics of the study population $(\mathrm{n}=567)$

\begin{tabular}{|lll|}
\hline Parameter & Frequency & Percentage \\
\hline Age & 231 & 40.7 \\
\hline $16-20$ & 101 & 17.8 \\
\hline $21-25$ & 15 & 2.6 \\
\hline $26-30$ & 3 & 0.5 \\
\hline $31-35$ & 217 & 38.3 \\
\hline $36-40$ & & 37.9 \\
\hline Religion & 215 & 62.1 \\
\hline Hindu & 352 & \\
\hline Muslim & & 80.6 \\
\hline Caste & 457 & 19.2 \\
\hline General & 109 & 0.2 \\
\hline SC/ST & 1 & 38.8 \\
\hline OBC & & 61.2 \\
\hline Type of Family & 220 & 100 \\
\hline Nuclear & 347 & \\
\hline Joint & 567 & \\
\hline Total & & \\
\hline
\end{tabular}


Table 2: The early Antenatal registration related factors

\begin{tabular}{|c|c|c|}
\hline Parameter & Frequency & Percentage \\
\hline \multicolumn{3}{|c|}{ Whether motivated for early ANC(n=567) } \\
\hline Yes & 476 & 83.9 \\
\hline No & 91 & 16.1 \\
\hline \multicolumn{3}{|l|}{ Motivator $(n=476)$} \\
\hline Self & 8 & 1.7 \\
\hline Husband & 90 & 18.9 \\
\hline Mother in law & 131 & 27.52 \\
\hline ASHA & 185 & 38.86 \\
\hline Others & 62 & 13.02 \\
\hline \multicolumn{3}{|c|}{$\begin{array}{l}\text { Whether attended Health facility after advice } \\
(n=476)\end{array}$} \\
\hline Yes & 463 & 97.3 \\
\hline No & 13 & 2.7 \\
\hline \multicolumn{3}{|c|}{ Designation of $1^{\text {st }}$ person giving care } \\
\hline ANM & 382 & 80.3 \\
\hline Government Doctor & 18 & 3.8 \\
\hline Private Doctor & 76 & 15.96 \\
\hline \multicolumn{3}{|c|}{ Place where registered for $\mathrm{ANC}(\mathrm{n}=476)$} \\
\hline Private clinic & 76 & 15.9 \\
\hline Sub centre & 356 & 74.8 \\
\hline $\mathrm{PHC} / \mathrm{BPHC}$ & 30 & 6.3 \\
\hline Higher Centres & 14 & 2.9 \\
\hline
\end{tabular}

Table 3: The table shows the ANC services received by the mothers $(n=565)$

\begin{tabular}{|lll|}
\hline Parameter & Frequency & Percentage \\
\hline BP measured atleast once & 565 & 100 \\
\hline Weight taken atleast once & 565 & 100 \\
\hline Urine examined atleast once & 558 & 98.8 \\
\hline Blood examined atleast once & 546 & 96.6 \\
\hline Abdomen examined atleast once & 548 & 96.9 \\
\hline EDD told to mother & 524 & 92.7 \\
\hline Two doses of TT given & 563 & 99.6 \\
\hline $\begin{array}{l}\text { Some form of Iron supplementation } \\
\text { done }\end{array}$ & 565 & 100 \\
\hline Advice about extra rest & 554 & 98.1 \\
\hline Advice about extra food & 554 & 98.1 \\
\hline
\end{tabular}

\section{References}

[1]. Pal S. eta al: Coverage of ante-natal care in a block of West Bengal using lot quality assurance sampling.Indian J Public Health. 2009 Oct-Dec;53(4):256-8.

[2]. International Institute for Population Sciences (IIPS) and Macro International. 2007. National Family Health Survey (NFHS-3), 2005-06: India: Volume I.Mumbai: IIPS.

[3]. ChandhiokNomita, DilloBalwan S, KamboIndra, SaxenaNirakra C. : Determinants of antenatal care utilization in rural areas a cross-sectional study from 28 districts (An ICMR task force) J obstetrics Gynecology of India, 56 (. 1): 47-52, 2006

[4]. Talwar R, Chitkara A, Khokhar A, Rasania S.K., and Sachdwa T.R. : Determinants of Utilization of ante- natal care services, amongst Attendees in a Publication Health and population sector hospital in Delhi: Health and population perspective and Issues , 28 (3):154- 163, 2005

[5]. Robertson S: Monitoring immunization services using the Lot Quality Technique. World Health Organization: Geneva, 1996. 